Article

\title{
Proteome Analysis of Human Natural Killer Cell Derived Extracellular Vesicles for Identification of Anticancer Effectors
}

\author{
Jung-Won Choi ${ }^{1,+}$, Soyeon Lim ${ }^{1,+}{ }^{\oplus}$, Jung Hwa Kang ${ }^{2}$, Sung Hwan Hwang ${ }^{2}$, Ki-Chul Hwang ${ }^{1}$, \\ Sang Woo Kim ${ }^{1, *}$ and Seahyoung Lee ${ }^{1, *}$ \\ 1 Institute for Bio-Medical Convergence, College of Medicine, Catholic Kwandong University, Gangneung-si, \\ Gangwon-do 210-701, Korea; jungwonjian@gmail.com (J.-W.C.); redclover77@hanmail.net (S.L.); \\ kchwang@cku.ac.kr (K.-C.H.) \\ 2 IMMUNISBIO Co. Ltd., B2F MTP Mall, International St. Mary's Hospital, \\ Incheon Metropolitan City 22711, Korea; kjunghwa@immunisbio.com (J.H.K.); \\ shhwang@immunisbio.com (S.H.H.) \\ * Correspondence: ksw74@cku.ac.kr (S.W.K.); sam1017@ish.ac.kr (S.L.) \\ + These authors contributed equally to this work.
}

Received: 5 October 2020; Accepted: 7 November 2020; Published: 9 November 2020

\begin{abstract}
Cancer immunotherapy is a clinically validated therapeutic modality for cancer and has been rapidly advancing in recent years. Adoptive transfer of immune cells such as $\mathrm{T}$ cells and natural killer (NK) cells has emerged as a viable method of controlling the immune system against cancer. Recent evidence indicates that even immune-cell-released vesicles such as NK-cell-derived exosomes also exert anticancer effect. Nevertheless, the underlying mechanisms remain elusive. In the present study, the anticancer potential of isolated extracellular vesicles (EVs) from expanded and activated NK-cell-enriched lymphocytes (NKLs) prepared by house-developed protocol was evaluated both in vitro and in vivo. Moreover, isolated EVs were characterized by using two-dimensional electrophoresis (2-DE)-based proteome and network analysis, and functional study using identified factors was performed. Our data indicated that the EVs from expanded and active NKLs had anticancer properties, and a number of molecules, such as Fas ligand, TRAIL, NKG2D, $\beta$-actin, and fibrinogen, were identified as effector candidates based on the proteome analysis and functional study. The results of the present study suggest the possibility of NK-cell-derived EVs as a viable immunotherapeutic strategy for cancer.
\end{abstract}

Keywords: extracellular vesicles; natural-killer-enriched lymphocytes (NKL); anticancer immunotherapy; proteome analysis

\section{Introduction}

Cancer immunotherapy designed to boost the immune system to produce antitumor effects has been scrutinized for its clinical viability [1]. Despite the disappointing results of early trials, immunotherapy is now rapidly advancing and being a clinically proven treatment modality for various types of cancers [2]. Immunotherapeutic strategies include, but are not limited to, cancer vaccines, oncolytic viruses, adoptive cell transfer, and administration of antibodies or recombinant proteins [2]. Especially, the adoptive transfer of immune cells such as T cells and natural killer (NK) cells has emerged as a targeted method of controlling the immune system against cancer [3]. 
NK cells, as a member of the lymphocytes of the innate immune system, have cytotoxic ability against both virus-infected cells and tumor cells [4]. Because of their ability to recognize and kill tumor cells without antigen exposure, they have been considered promising agents for cell-based cancer therapies [4]. However, the scarcity of NK cells in human lymphocytes, their changing phenotype, and their impaired functionality during cancer progression necessitates the development of protocols to activate and expand NK cells to sufficient numbers ex vivo for adoptive transfer $[4,5]$. We have developed a feeder-free NK cell expansion system where clinically viable NK cells are isolated and cultured from human peripheral blood mononuclear cells (PBMCs) for NK studies [6].

Another approach to bypass the current limitations of NK-cell-based immunotherapy is the use of NK-cell-derived extracellular vesicles (EVs) without using actual NK cells. EVs are found in various body fluids and originate directly from the plasma membrane of the cell [7]. They participate in intercellular communication by transporting mRNA, miRNA, and proteins $[8,9]$ and have various functions depending on the cell types they are derived from [10]. In the tumor microenvironment, all cells, including endothelial cells, pericytes, and immune cells, as well as tumor cells, release EVs [11]. While tumor-cell-derived EVs mediate angiogenesis, invasion, immune escape, chemotherapy resistance, and phenotypic modification of recipient cells [12], immune-cell-derived EVs suppress tumor progression by direct or indirect mechanisms [11]. Such effects of immune-cell-derived EVs enable one to create new methods for cancer therapy. However, the heterogeneity of immune-cell-derived EVs and their unclarified mechanisms prevent them from being an effective therapeutic modality against cancer. Therefore, the characterization of immune-cell-derived EVs would be the first step for assessing their therapeutic potential against cancers.

Immune-cell-derived EVs are reported to have anticancer properties [11,13]. In the present study, we examined the anticancer potential of EVs isolated from human NK-cell-enriched lymphocytes (NKLs) prepared by a house-developed protocol. EVs can be classified based on their sizes as exosomes $(30-100 \mathrm{~nm})$, microvesicles $(100-1000 \mathrm{~nm})$, and apoptotic bodies (>1000 nm) [14]. Exosomes are generated through fusion with the plasma membrane of specific endosomal compartments [15], and microvesicles are produced via an outward budding from the plasma membrane [16]. Although their cargo, membrane composition, and surface molecules are distinct with some overlapping features, exosomes and microvesicles often share functions, and their sizes can be similar [14].

In the present study, we characterized EVs isolated from expanded and activated NKL using two-dimensional electrophoresis (2-DE)-based proteome analysis and evaluated their therapeutic potential against cancer both in vitro and in vivo to identify potent anticancer effectors of NKL-derived EVs that may help to develop an anticancer cocktail to treat cancer even without using the original EVs.

\section{Results}

\subsection{Preparation of Ex Vivo Expanded NKLs}

To expand NKLs from PBMCs, blood-isolated PBMCs were cultured in the presence of agonistic antibodies against activating receptors (CD16 and CD56) and a natural cytotoxic receptor (NKp46) of NK cells, selected cytokines (IL-2, IL-12, and IL-18), and autologous human plasma. After 2 weeks of culture, the total cell number of expanded NKLs increased approximately 115-fold compared to that of initially isolated PBMCs $\left(2.1 \times 10^{7}\right.$ vs. $2.5 \times 10^{9}$ cells, Figure $\left.1 \mathrm{~A}\right)$. The proportion of NK (CD16+CD56+/CD3-), NKT (natural killer T cell, CD16+CD56+/CD3+), and T cells (CD16-CD56-/CD3+) in initially isolated PBMCs and NKLs was determined using flow cytometry. In the initially isolated PBMCs, the proportions of NK cells and NKT cells were $18.3 \pm 5.6 \%$ and $5.8 \pm 7.6 \%$, respectively. After 2 weeks of cultivation, these proportions increased to $57.6 \pm 17.4 \%$ and $16.2 \pm 8 \%$, respectively, in NKLs (Figure 1B,C). By contrast, the percentage of T cells in NKLs slightly decreased compared to PBMCs (Figure 1D), indicating that NK/NKT cells were preferentially expanded compared to T cells under the given culture conditions. We used a CD16/CD56 cocktail for this particular flow cytometry analysis due to a limited multicolor processing capacity of the device, as we previously found that the expression patterns of 
CD3/CD56-stained PBMCs and CD3/CD16-stained PBMCs were highly identical (data not shown). Nevertheless, the possibility of mixed-up presentation of CD56dimCD16+ cells and CD56brightCD16cells, as well as of just-activated T cells being recognized as NKT cells, exists. This remains one of the limitations of this study and should be improved for further studies.

A

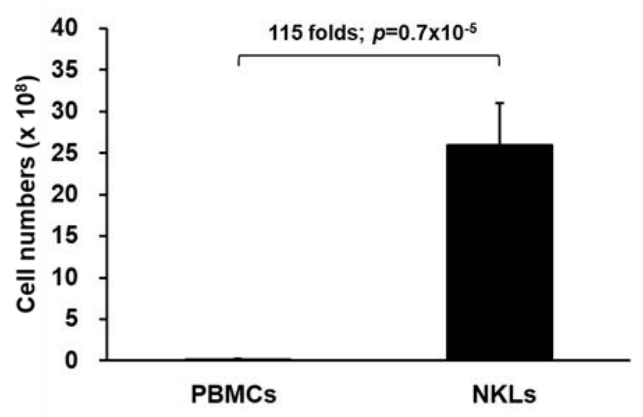

C

\begin{tabular}{|c|c|c|c|c|c|c|}
\hline & Donor1 & Donor2 & Donor3 & Donor4 & Donor5 \\
\hline \multirow{3}{*}{ 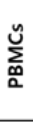 } & NK & 17.7 & 20.5 & 24.4 & 19.6 & 9.3 \\
\hline & NKT & 2.7 & 0.6 & 19.1 & 1.0 & 5.2 \\
\hline & $\mathrm{T}$ & 47.4 & 42.6 & 15.8 & 56.5 & 46.9 \\
\hline \multirow{3}{*}{$\vec{v}$} & NK & 66.7 & 40.0 & 80.0 & 61.0 & 40.1 \\
\hline & NKT & 18.8 & 18.2 & 6.5 & 10.6 & 27.1 \\
\hline & $T$ & 13.9 & 38.3 & 12.7 & 27.5 & 29.7 \\
\hline
\end{tabular}

D

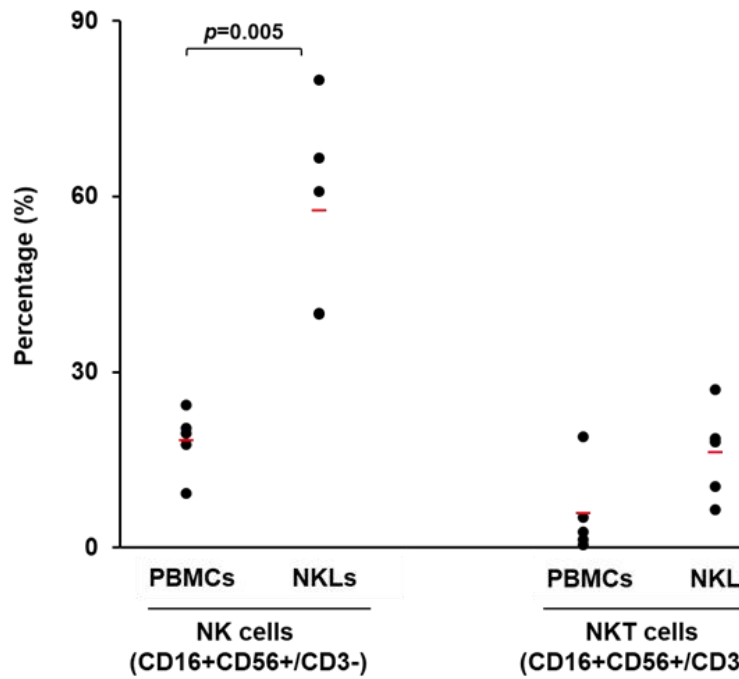

B

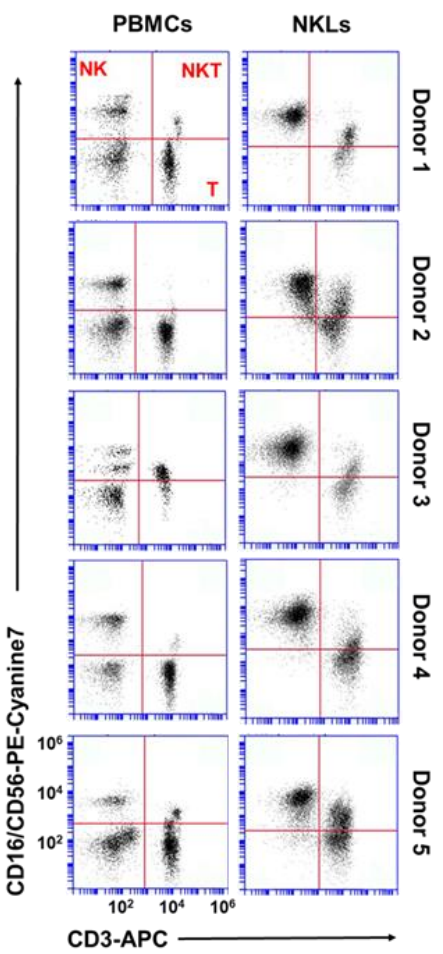

Figure 1. Characterization of expanded natural killer (NK)-cell-enriched lymphocytes (NKLs). (A) Comparison of total cell numbers. (B) Distribution of NK (CD3-CD16+CD56+), NKT (CD3+CD16+CD56+), and T cells (CD3+CD16-CD56-) compared between peripheral blood mononuclear cells (PBMCs) and NKLs from 5 individuals. (C) Percentages of NK, NKT, and T cells before and after the in vitro expansion. (D) The mean percentage of each group is indicated with red bars. Significant differences between PBMCs and NKLs were determined via analysis of variance (ANOVA). 


\subsection{Isolation of EVs from Culture Medium of NKLs}

EVs were isolated from the culture medium of NKLs following the protocol shown in Figure 2A. Primary verification of isolated EVs was done by immunoblot analysis using EV markers such as selectins, integrins, and CD40 known to be contained in EVs [9]. CD40 ligand (CD154) was detectable in control, EV 1, and EV 3. For integrin $\alpha 5$ (CD49a), all the samples except EV 2 expressed CD49a. For all other markers examined, although there was interindividual difference, most of the NKL-derived EVs and control EVs expressed examined markers, namely L-selectin (CD62L), integrin $\alpha 1$ (CD49a), integrin $\beta 1$ (CD29), and CD63 tetraspanin, a common exosome marker [17] (Figure 2B).
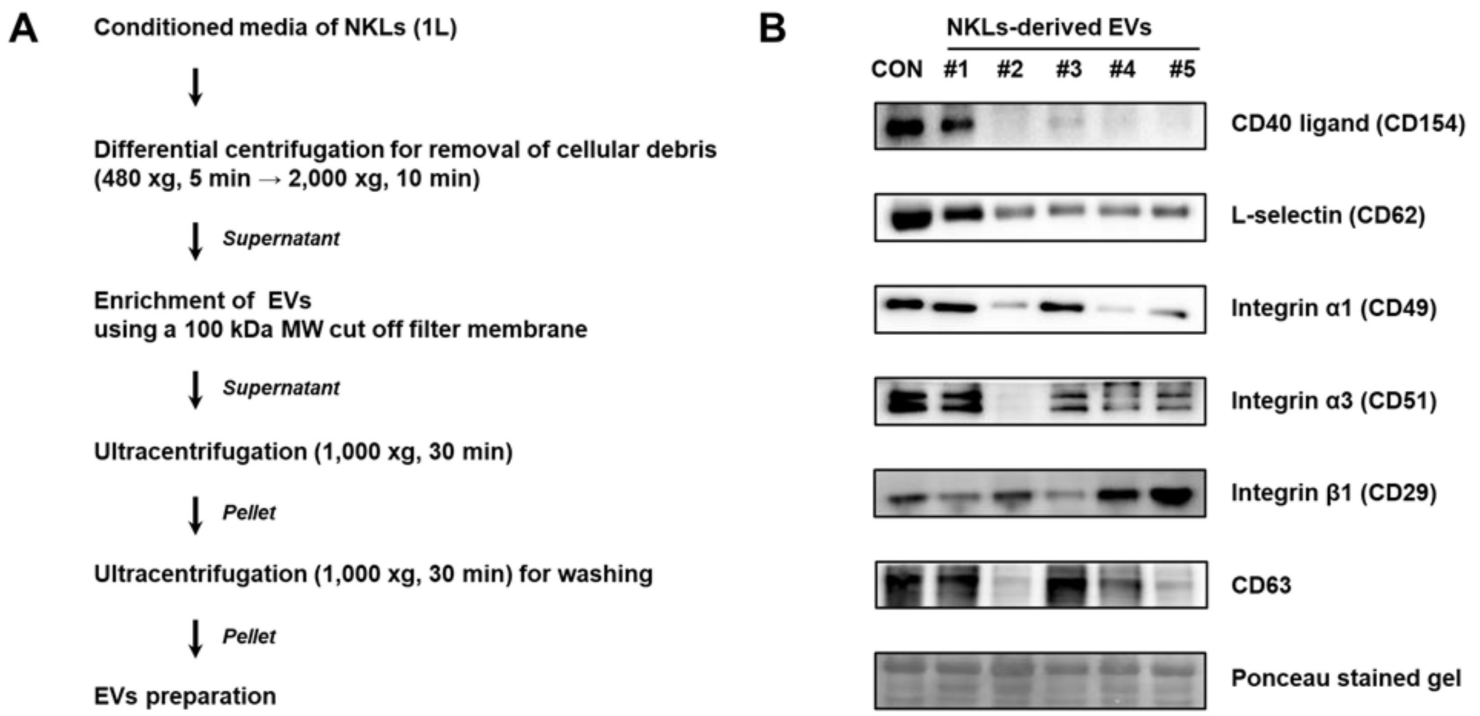

Figure 2. (A) Experimental scheme for extracellular vesicle (EV) isolation from conditioned medium of NKLs (B) Expression of markers in isolated EVs. Control EVs (CON) were prepared from concentrated medium containing pooled autologous plasma of 5 individuals.

\subsection{Anticancer Effect of NKL-Derived EVs In Vitro and In Vivo}

To evaluate the anticancer potential of NKL-derived EVs in vitro, EVs at four different concentrations $(2,5,10$, and $20 \mu \mathrm{g} /$ well $)$ were applied to five different cancer cell lines with different origins (HepG2, liver; SW-620, colon; MKN-74, stomach; MCF-7, breast; T98G, brain). As the concentration of EVs increased, the cell viability of all five cancer cell lines significantly decreased, while lactate dehydrogenase (LDH) release significantly increased (Figure 3A). Furthermore, in in vivo study using an MCF-7-based breast cancer model, NKL-derived EVs started to significantly suppress the tumor growth from 2 weeks after the injection and thereafter $\left(388.3 \pm 58 \mathrm{~mm}^{3}\right.$ vs. $248.5 \pm 78.4 \mathrm{~mm}^{3}$ in control group and NKL-derived EV group, respectively) (Figure 3B). The final tumor mass was significantly smaller in the NKL-derived EV group $(0.27 \pm 0.05 \mathrm{~g})$ than in the control group $(0.44 \pm 0.11 \mathrm{~g})$ as well (Figure 3B). Since no healthy, normal cells were analyzed in the cytotoxicity assays to exclude an unspecific cytotoxic effect of the NKL-derived EVs in the present study, there can be concern. However, regarding possible cytotoxicity of EVs on healthy normal cells, we have examined the cytotoxicity of NKL-derived EVs prepared by using the same protocol on human adipose-derived stem cells (ASCs) in a different study. According to our unpublished data, the NKL-derived EVs had no significant cytotoxic effect on human ASCs for up to $48 \mathrm{~h}$ of co-culture, and therefore, it was assumed that there is no significant cytotoxicity of the NKL-derived EVs against healthy, normal cells. 


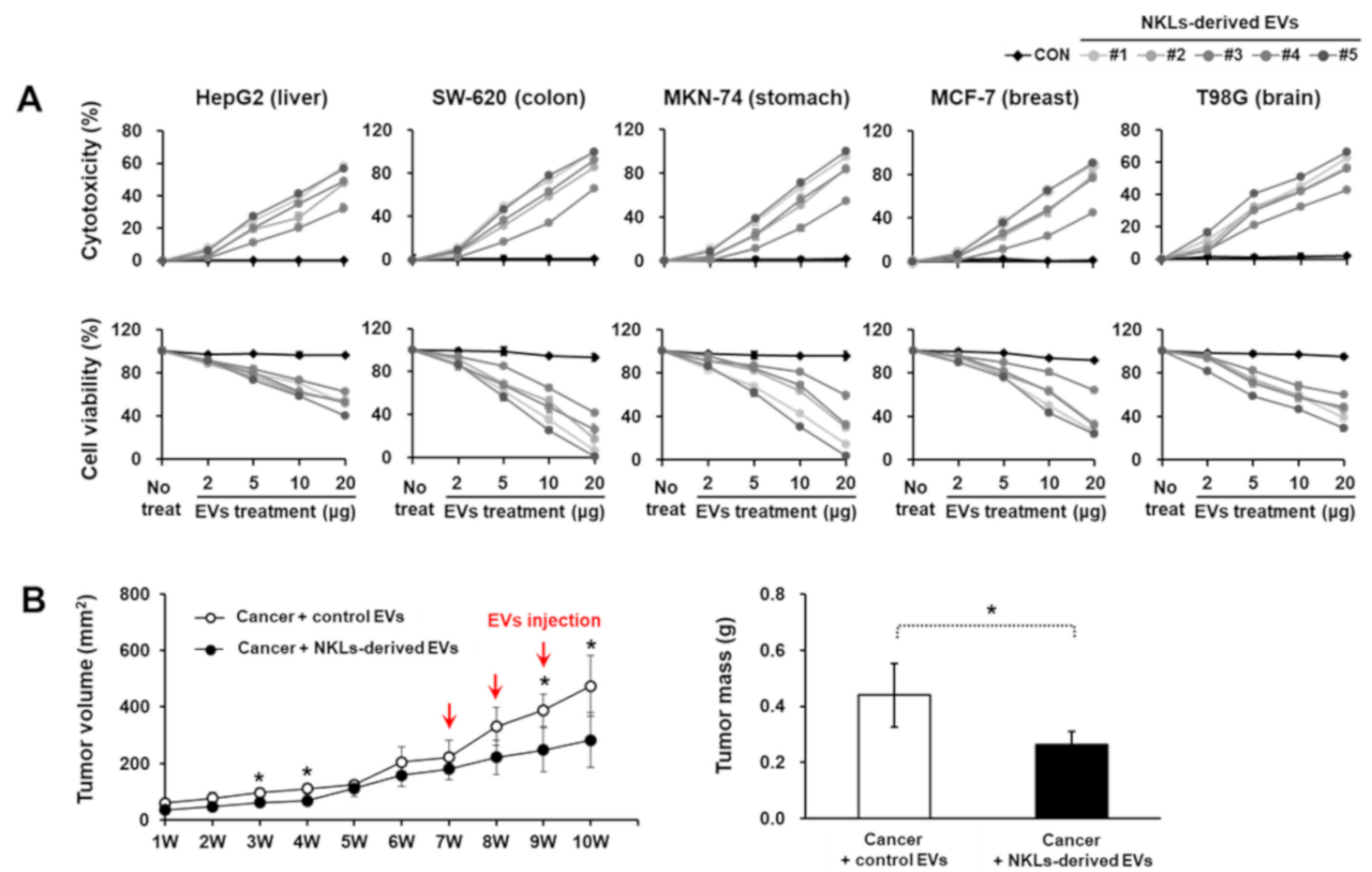

Figure 3. Cytotoxic potential of isolated EVs against cancer cell lines and cancer animal model. (A) Isolated individual EVs were used to treat 5 cancer cell lines from different tissues; cytotoxicity of isolated EVs against cancer cells was observed, and cell viability of cancer cells against isolated EVs was measured. Experiments were performed in triplicate. Significant differences between untreated cancer cells and EV-treated cancer cells were determined via ANOVA. (B) The volume of tumor and tumor mass after administration of vehicle (PBS) and NKL-derived EVs in MCF-7-cell-injected female athymic nude mice. The tumor volume was monitored every week for 10 weeks ( $n=4$ for each group), and tumor mass was measured at the end of the animal study. Significant differences between groups were determined via ANOVA, with $p$-values indicated as $* p<0.05$.

\subsection{Expression of Anticancer-Activity-Related Proteins in NKL-Derived EVs}

To identify the effector proteins presumably account for the observed anticancer effect of NKL-derived EVs in vitro and in vivo, the expression of well-known anticancer mediators, such as death receptors (Fas/APO-1/CD95, DR4/CD261/TRAILR1, and DR5/CD262/TRAILR2) and ligands (Fas ligand/CD178 and TRAIL), activating receptors (NKG2D/CD314 and DNAM-1/CD226), natural cytotoxicity receptors (NKp44/CD336 and NKp46/CD355), and cytokines (IFN- $\gamma$, TNF- $\alpha$, and IL-6) was examined by using immunoblot analysis (Figure 4). Although there was individual variation among five donors, the expression of death receptors and ligands, activating and natural cytotoxicity receptors, and cytokines was prominent in the NKL-derived EVs, while none of them were detected in control EVs (Figure 4). 

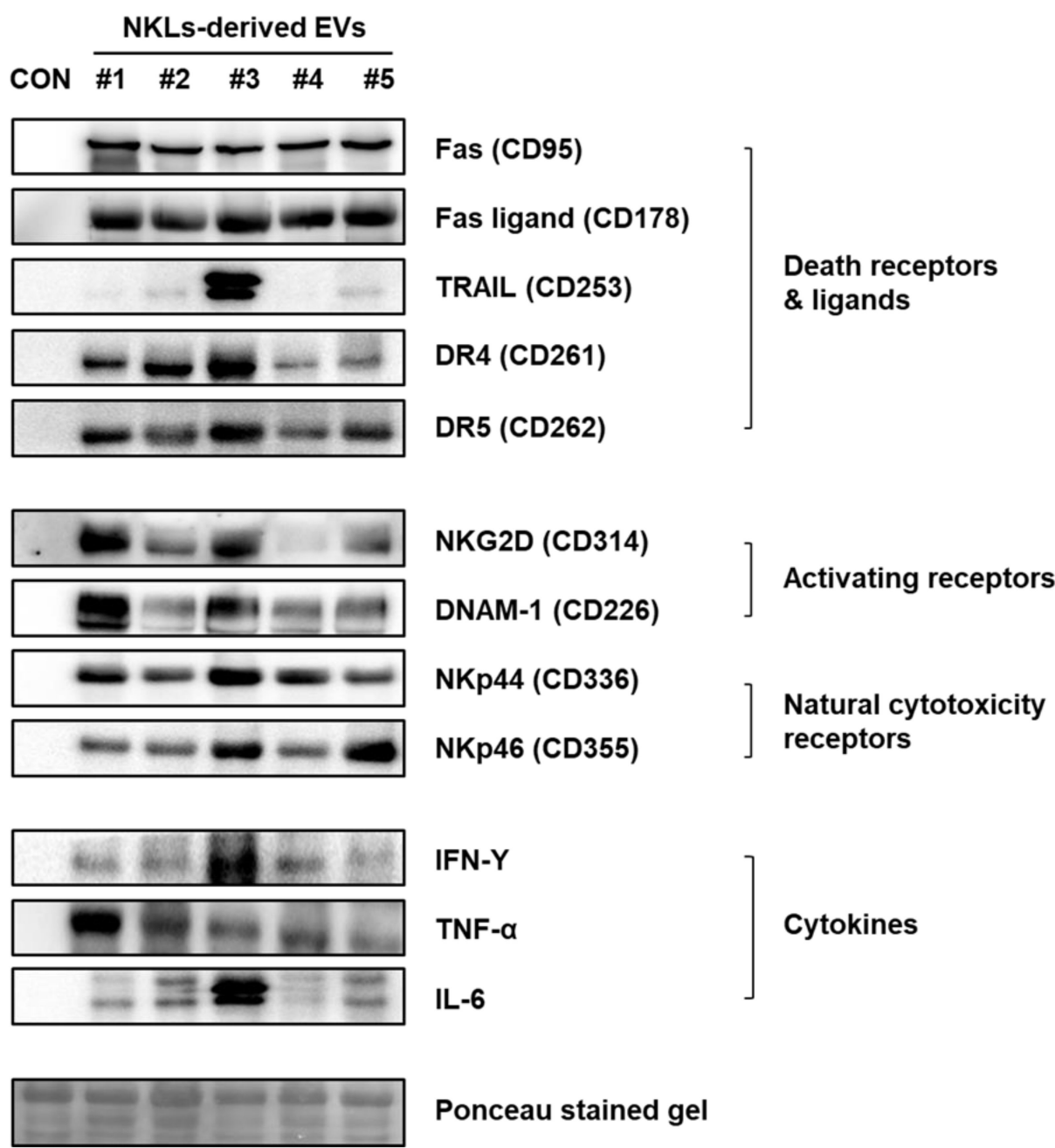

Ponceau stained gel

Figure 4. Expression of receptors, ligands, and cytokines related to cytotoxicity against cancer cells in NKL-derived EVs. CON: control EVs.

\subsection{Separation and Identification of Significantly Increased EV Proteins Using Proteome Analysis}

To find other novel proteins that might have facilitated the tumor-killing of NKL-derived EVs, 2-DE-based proteome analysis was performed using isolated EVs. EV proteins were separated by 2-DE, and nearly 630 individual spots (mass ranging from 6 to $240 \mathrm{kDa}$ and $\mathrm{pH}$ between 4 and 7) were detected (Figure 5A). Among them, a total of 49 spots significantly increased in the NKL-derived EV, and 37 of them were identified by peptide mass fingerprinting (PMF) (Figure 5B (also see Figure S1 for a high-resolution image) and Table 1). It was interesting to notice that 5 spots (out of 27) were different fibrinogen isotypes and 12 spots were $\beta$-actin fragments (and there was an additional $1 \gamma$-actin fragment) (Table 1). For functional classification of the identified proteins, a Gene-Term 2D Heat map was constructed using DAVID (https://david.ncifcrf.gov/) (Figure 5C). Most of the identified proteins could be categorized under the annotation terms of extracellular space, blood microparticle, and plasma membrane based on the enrichment scores. Additional immunoblot analysis to exclude the possibility of technical errors and artificial effects during proteome analysis was performed for eight selected proteins of interest, namely $\beta$-actin, FGG, FGB, Apo A-IV, Apo E, L-plastin, VCP, and HSP90 $\alpha / \beta$, and the results of the immunoblot analysis also confirmed that those proteins were highly expressed in NKL-derived EVs compared to the control (Figure 5D). 
A

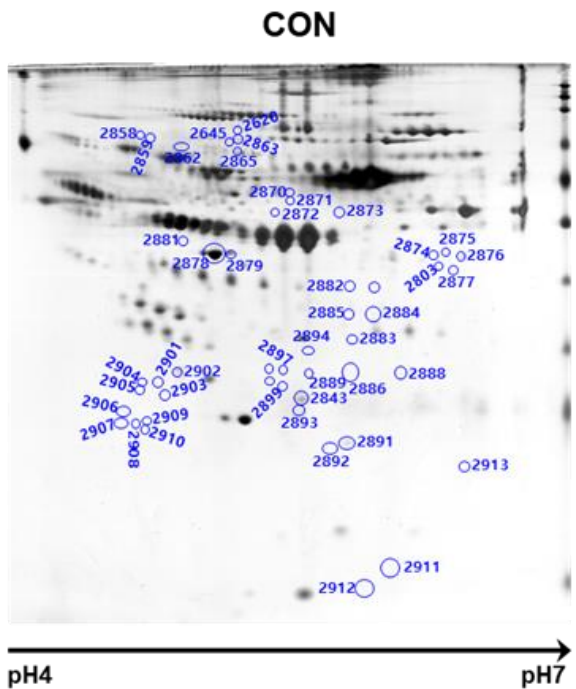

B

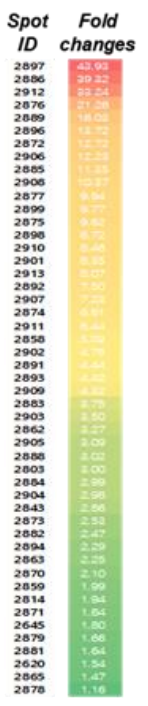

\section{C}
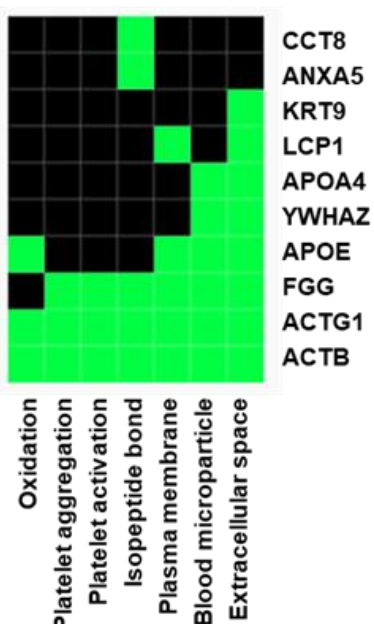

Corresponding gene-term association positively reported Corresponding gene-term association not reported yet

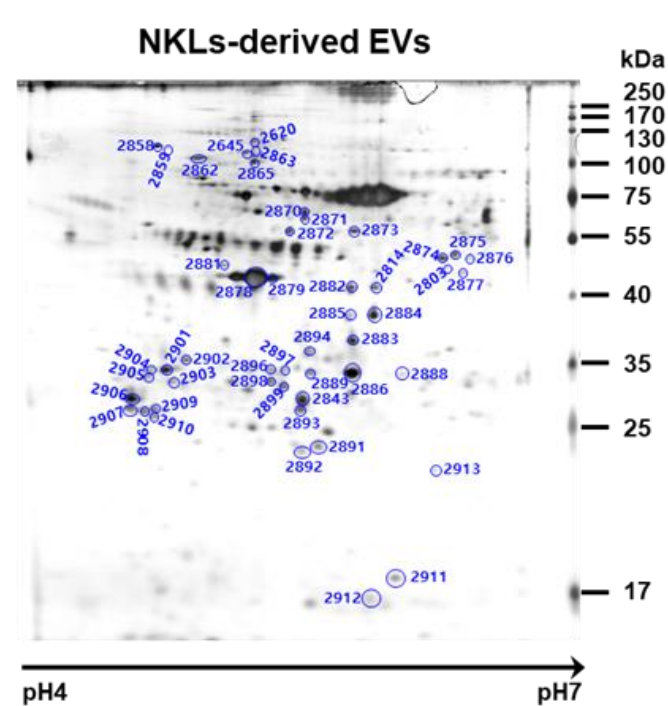

D

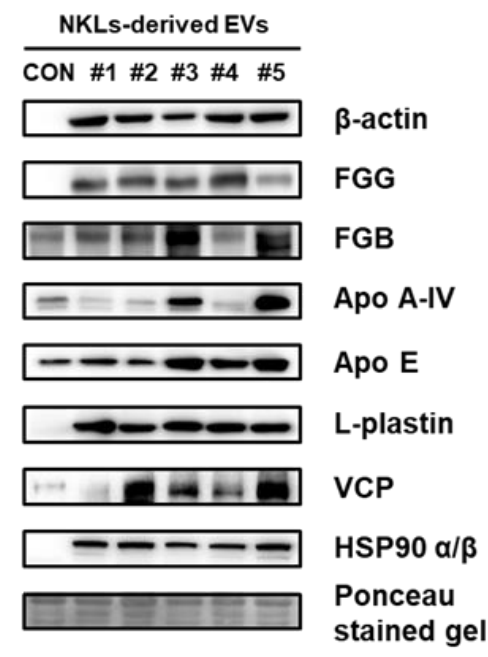

Figure 5. Proteome analysis of NKL-derived EVs. (A) Representative silver-stained two-dimensional electrophoresis (2-DE) gel images of control EVs (CON) and NKL-derived EVs (B) Spots with increased intensity and their fold changes in NKL-derived EVs compared to CON. A high-resolution image along with 2-DE gel images is presented in Figure S1. (C) Gene-Term 2D Heat map view using DAVID Bioinformatics resources. (D) The expression of increased proteins was confirmed by immunoblot analysis. 2-DE experiments were performed in triplicate per individual. 
Table 1. List of identified proteins in isolated EVs by peptide mass fingerprinting (PMF) analysis.

\begin{tabular}{|c|c|c|c|c|c|c|c|c|c|c|}
\hline \multirow{2}{*}{ Spot ID } & \multirow{2}{*}{ Protein Name } & \multirow{2}{*}{ Gene Name } & \multirow{2}{*}{ Calculated pI } & \multirow{2}{*}{$\begin{array}{l}\text { Normimal } \\
\text { Mass }(\mathrm{Mr})^{1)}\end{array}$} & \multirow{2}{*}{$\begin{array}{c}\text { Sequence } \\
\text { Coverage (\%) }\end{array}$} & \multirow{2}{*}{ Score ${ }^{2)}$} & \multicolumn{2}{|c|}{ Protein Intensity $(\% \mathrm{vol})^{3)}$} & \multirow{2}{*}{$\begin{array}{l}\text { Fold Change } \\
\text { (NKLs/CON) }\end{array}$} & \multirow{2}{*}{$p$ Value $^{4)}$} \\
\hline & & & & & & & CON & NKLs & & \\
\hline \multirow{2}{*}{2897} & Fibrinogen gamma chain, isoform CRA_o & \multirow{7}{*}{ FGG } & 5.54 & 47971 & 33 & 109 & \multirow[b]{2}{*}{0.03} & \multirow[b]{2}{*}{1.16} & \multirow[b]{2}{*}{43.94} & \multirow[b]{2}{*}{0.021} \\
\hline & Fibrinogen gamma chain, isoform $\mathrm{CRA}_{-} \mathrm{j}$ & & 6.02 & 48277 & 33 & 109 & & & & \\
\hline 2886 & Fibrinogen beta chain, isoform CRA_g & & 8.63 & 50940 & 18 & 84 & & 468 & 39.32 & 0.001 \\
\hline & Fibrinogen beta chain, isoform CRA_d & & 8.33 & 52759 & 18 & 84 & 0.12 & 4.68 & & \\
\hline 2876 & Fibrinogen beta chain, isoform CRA_d & & 8.33 & 52759 & 24 & 98 & 0.01 & 0.27 & 21.26 & 0.022 \\
\hline 2889 & \multirow{7}{*}{ Fibrinogen beta chain, isoform CRA_g } & & \multirow{7}{*}{8.63} & \multirow{2}{*}{50940} & 28 & 96 & 0.08 & 1.21 & 16.03 & 0.011 \\
\hline 2888 & & & & & 22 & 84 & 0.14 & 0.44 & 3.02 & 0.049 \\
\hline 2896 & & \multirow{12}{*}{ АСТВ } & & & 34 & 81 & 0.10 & 1.38 & 13.72 & 0.035 \\
\hline 2885 & & & & & 33 & 107 & 0.08 & 0.86 & 11.35 & 0.016 \\
\hline 2898 & & & & & 36 & 98 & 0.07 & 0.63 & 8.72 & 0.004 \\
\hline 2901 & & & & & 39 & 142 & 0.17 & 1.43 & 8.35 & 0.001 \\
\hline 2893 & & & & & 43 & 199 & 0.20 & 0.88 & 4.42 & 0.006 \\
\hline 2884 & \multirow{7}{*}{ АСТВ protein, partial } & & \multirow{7}{*}{5.55} & \multirow{7}{*}{40536} & 37 & 109 & 0.53 & 1.57 & 2.99 & 0.062 \\
\hline 2882 & & & & & 50 & 142 & 0.42 & 1.04 & 2.47 & 0.002 \\
\hline 2814 & & & & & 28 & 77 & 0.68 & 1.31 & 1.94 & 0.005 \\
\hline 2879 & & & & & 46 & 136 & 2.02 & 3.34 & 1.66 & 0.027 \\
\hline 2620 & & & & & 28 & 98 & 0.29 & 0.44 & 1.54 & 0.003 \\
\hline 2865 & & & & & 41 & 108 & 0.34 & 0.50 & 1.47 & 0.049 \\
\hline 2878 & & & & & 48 & 170 & 13.68 & 15.87 & 1.16 & 0.040 \\
\hline 2872 & L-plastin polypeptide & LCP1 & 5.41 & 64352 & 20 & 100 & 0.03 & 0.35 & 12.72 & 0.027 \\
\hline 2906 & Tyrosine 3-monooxygenase/tryptophan 5-monooxygenase & & & & 35 & 116 & 0.10 & 1.27 & 12.23 & 0.052 \\
\hline 2910 & activation protein zeta polypeptide & YWHAZ & 4.73 & 27867 & 31 & 89 & 0.05 & 0.45 & 8.46 & 0.023 \\
\hline 2908 & $\begin{array}{l}\text { Tyrosine 3-monooxygenase/tryptophan 5-monooxygenase } \\
\text { activation protein epsilon }\end{array}$ & YWHAE & 4.63 & 29326 & 27 & 68 & 0.06 & 0.67 & 10.37 & 0.016 \\
\hline 2877 & PA2G4 protein, partial & PA2G4 & 9.08 & 45579 & 18 & 105 & 0.03 & 0.32 & 9.94 & 0.005 \\
\hline 2899 & Cytokeratin 9 & KRT9 & 5.19 & 62320 & 30 & 85 & 0.09 & 0.87 & 9.77 & 0.003 \\
\hline 2907 & Proteasome (prosome, macropain) subunit, alpha type, 5 & PSMA5 & 4.74 & 26579 & 46 & 139 & 0.09 & 0.65 & 7.23 & 0.026 \\
\hline 2874 & Human rab GDI & GDI2 & 5.94 & 51088 & 40 & 189 & 0.11 & 0.72 & 6.81 & 0.002 \\
\hline 2858 & Heat shock protein HSP 90-beta precursor, partial & HSP90AB1 & 4.73 & 90309 & 27 & 141 & 0.14 & 0.69 & 5.03 & 0.001 \\
\hline 2862 & Heat shock protein HSP 90-beta isoform c & HSP90AB1 & 4.98 & 82611 & 29 & 135 & 0.41 & 1.34 & 3.27 & 0.034 \\
\hline 2902 & Annexin A5 & ANXA5 & 4.94 & 35971 & 62 & 256 & 0.12 & 0.58 & 4.78 & 0.015 \\
\hline 2891 & Glutathione S-transferase & GSTM4 & 5.43 & 23595 & 61 & 113 & 0.10 & 0.47 & 4.44 & 0.026 \\
\hline 2883 & L-lactate dehydrogenase $B$ chain isoform LDHB & LDHB & 5.71 & 36900 & 32 & 142 & 0.31 & 1.15 & 3.75 & 0.006 \\
\hline 2843 & Gamma-actin, partial & ACTG1 & 5.65 & 26147 & 52 & 147 & 1.04 & 2.97 & 2.86 & 0.014 \\
\hline 2873 & $\begin{array}{l}\text { Protein disulfide isomerase family A, member 3, isoform } \\
\text { CRA b }\end{array}$ & PDIA3 & 6.42 & 55328 & 42 & 230 & 0.41 & 1.04 & 2.53 & 0.004 \\
\hline & Protein disulfide isomerase family A, member 3 , isoform & PDIA3 & 6.78 & 54454 & 42 & 230 & & & & \\
\hline 2894 & Apolipoprotein E & APOE & 5.81 & 36242 & 38 & 104 & 0.43 & 0.99 & 2.29 & 0.049 \\
\hline 2870 & T-complex protein 1 subunit epsilon isoform $\mathrm{d}$ & CCT5 & 5.86 & 49951 & 38 & 126 & 0.34 & 0.72 & 2.10 & 0.017 \\
\hline 2871 & T-complex protein 1 subunit theta isoform 2 & ССТ8 & 5.25 & 58179 & 29 & 176 & 0.28 & 0.52 & 1.84 & 0.029 \\
\hline 2645 & Valosin-containing protein & VCP & 5.19 & 89972 & 30 & 172 & 0.25 & 0.46 & 1.80 & 0.046 \\
\hline 2881 & Apolipoprotein A-IV & APOA4 & 5.23 & 45307 & 40 & 147 & 0.26 & 0.42 & 1.64 & 0.046 \\
\hline
\end{tabular}

1) The nominal mass is the integer mass of the most abundant naturally occurring stable isotope of an element. The nominal mass of a molecule is the sum of the nominal masses of the elements in its empirical formula. ${ }^{2)}$ MASCOT probability-based MOWSE (molecular weight search) score calculated for PMF. Protein score is $-10 * \log (\mathrm{P})$, where $\mathrm{P}$ is the probability that the observed match is a random event and greater than 66 are significant $(p<0.05) .{ }^{3)}$ Protein intensity indicated average of controls and 5 individuals. ${ }^{4)}$ Statistical significance between control EVs (CON) and NKLs-derived EVs (NKLs) was determined by a $t$-test. 


\subsection{Functional Verification of the NKL-Derived EV Proteins Using Neutralizing Antibodies}

To verify whether the proteins of the NKL-derived EV actually contributed to the observed anticancer effect, a functional study using neutralizing antibodies was conducted. Although the results were inconsistent and showed an intraindividual variability, the proteins examined contributed to the observed anticancer effect of NKL-derived EVs to a certain extent (Figure S2). Interestingly, even the neutralizing antibodies against $\beta$-actin and fibrinogen negated the anticancer effect of EVs, especially in liver cancer cells and stomach cancer cells (Figure 6). Furthermore, treatment with recombinant $\beta$-actin and fibrinogen showed marginal, but statistically significant, anticancer effect in certain types of cancer cells (Figure 7), suggesting that $\beta$-actin and fibrinogen actually contributed to the observed anticancer effect of the NKL-derived EVs. On the other hand, when the data were analyzed as pooled data, all the significance observed was completely masked (data not shown), and this also indicated that the observed effects in single patients were donor-specific.

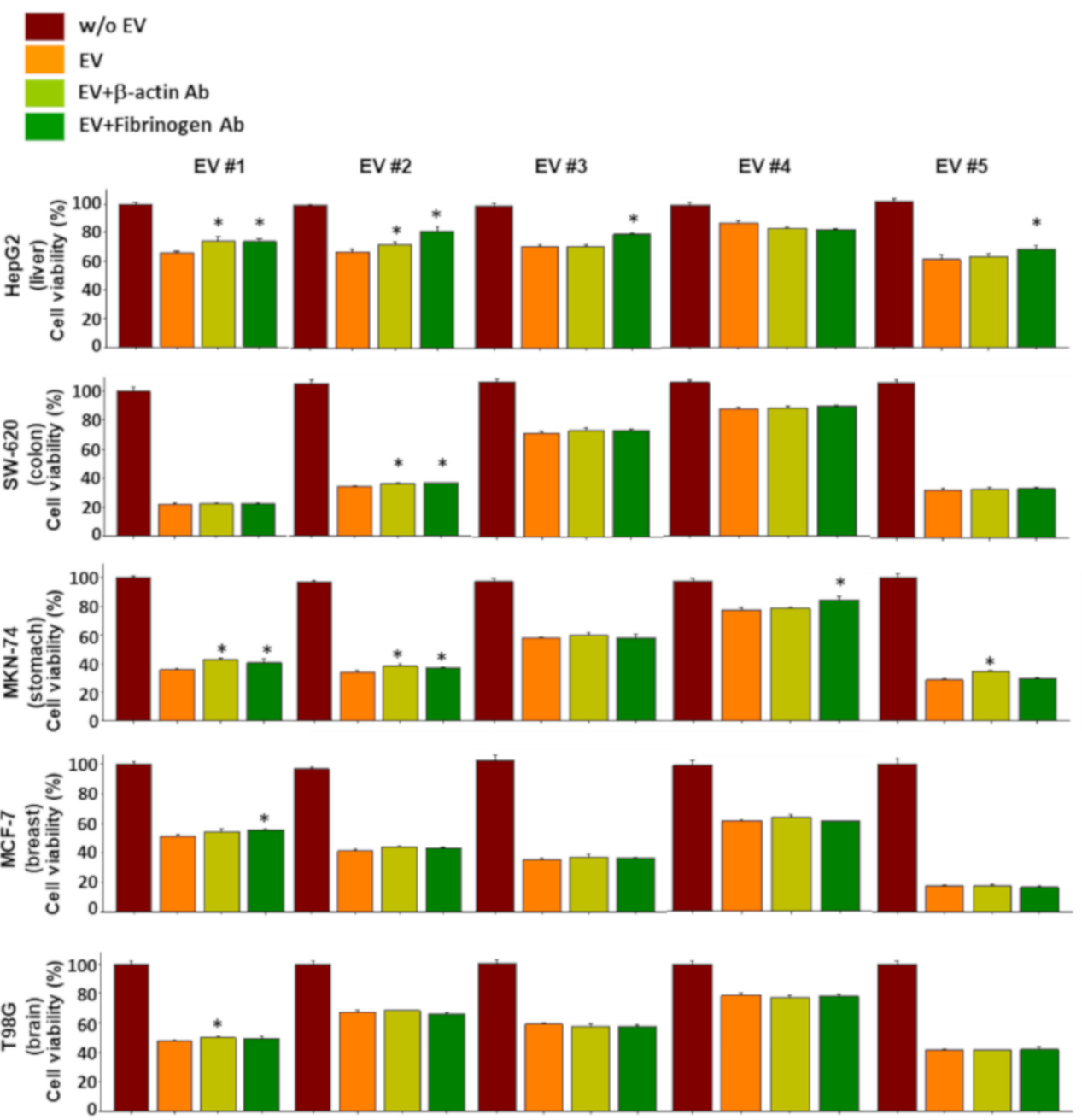

Figure 6. Effect of neutralizing antibodies against $\beta$-actin and fibrinogen on the anticancer effect of EVs. Individual EVs mixed with/without neutralizing antibodies specific to $\beta$-actin and fibrinogen were applied to 5 different types of cancer cells, and viability of cancer cells was measured. Experiments were performed in triplicate. Significant differences were determined via ANOVA, with $p$-values indicated as ${ }^{*} p<0.05$ compared to the EVs without neutralizing antibodies. 

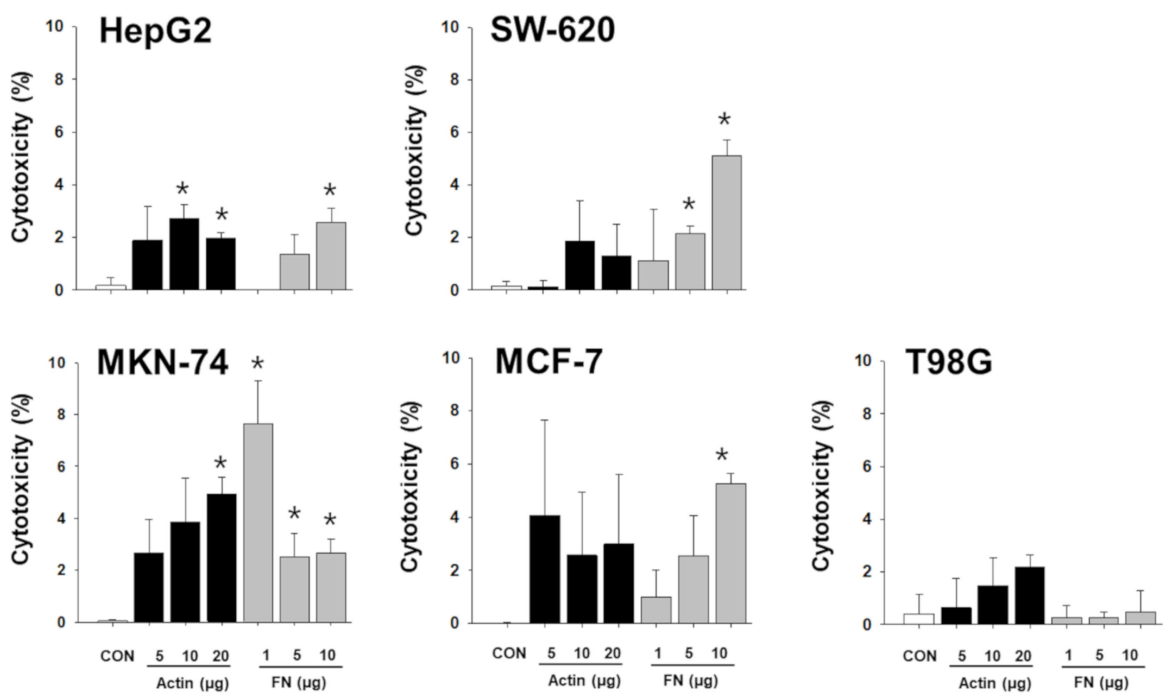

Figure 7. Cytotoxic effect of recombinant $\beta$-actin and fibrinogen on different types of cancer cells. Varying concentrations of recombinant $\beta$-actin and fibrinogen were applied to 5 different types of cancer cells, and cytotoxicity on cancer cells was measured. Experiments were performed in triplicate. Significant differences were determined via ANOVA, with $p$-values indicated as ${ }^{*} p<0.05$ compared to untreated control (CON). Actin: $\beta$-actin, FN: fibrinogen.

\section{Discussion}

In the present study, the isolated EVs were found to express commonly known microvesicle markers such as selectins, integrins and the CD40 ligand [9], and exosome marker CD63 expression was also detected (Figure 2B). The CD63 is a member of the tetraspanin superfamily of integral membrane proteins and is known as an exosome marker along with CD9 and CD81 [17], but it was first known as a marker of platelet activation [18]. Since the EV isolation protocol used in the present study did not have a platelet depletion step (Figure 2A) and CD63 is not only enriched in the platelet-derived exosomes but also present on platelet-derived microvesicles [19], it was assumed that the isolated EVs were mostly microvesicles rather than a mixture of microvesicles and exosomes.

Since our in vitro expansion protocol involves culturing PBMCs in the presence of donor's plasma, which also may contain EVs, concerns can be raised about possible contamination of samples with EVs from donor's plasma. This issue is closely linked to the half-life of EVs (including both exosomes and microvesicles), and a previous study examining the half-life of exosomes indicated that exosomes have an average half-life of $4 \mathrm{~min}$ and approximately $10 \%$ of them remain intact after $4 \mathrm{~h}$ [20]. Furthermore, microvesicles may have an even shorter half-life because their membrane lipids can be hydrolyzed by blood-borne phospholipases [21,22]. Considering that our protocol to produce NKLs uses $0.5 \%$ human plasma at the final step and the cells are cultured for additional 6-7 days before harvesting, contamination of the sample by EVs from the donor's plasma is less likely.

To date, a variety of immune-cell-derived EVs has been reported to suppress tumor progression [11]. Dendritic cell (DC)-derived EVs with major histocompatibility complex (MHC) class I and class II peptide complexes were able to prime other immune cells and activate an antitumor immune response [23]. Phase I clinical trials have demonstrated the safety of using DC-derived exosomes in patients with metastatic melanoma [24] and lung cancer [25], and phase II clinical trials have shown that DC-derived exosomes can increase NK cell functions in non-small-cell carcinoma patients [26]. The combination of exosomes and the invariant NKT immune cell ligand $\alpha$-galactosylceramide $(\alpha \mathrm{GC})$ induced potent NK and $\gamma \delta \mathrm{T}$ cell innate immune responses in vitro and in vivo, and they increased survival by increasing antigen-specific CD8+ T cell tumor infiltration while decreasing tumor growth in an ovalbumin (OVA)-expressing tumor-bearing mouse model [27]. According to a recent study, NK92-cell-derived exosome also exerts antitumor effects against aggressive melanoma in vitro and 
in vivo, while not showing any significant cytotoxicity against healthy, normal cells [28]. Therefore, it seems that NK-cell-derived exosomes can preferentially kill tumor cells over normal, healthy cells, suggesting that NK-cell-derived exosomes can discriminate between tumor cells and non-tumor cells [29] and that the possibility of NKL-derived EVs having cytotoxicity against normal, healthy cells is very small. Nevertheless, the underlying mechanisms of EVs derived from immune cells remain largely unknown, and the identification of anticancer effector molecules contained in the EVs might be the first step to comprehend the mechanism.

To find effector molecules responsible for the observed in vitro and in vivo anticancer effect of NKL-derived EVs, some of the well-known candidate molecules were examined first. NK cells express activating (NKG2D and DNAM-1) and inhibitory receptors (KIR and CD94) and natural cytotoxicity receptors (NKp30, NKp44, and NKp46). These receptors recognize MHC class I and related molecules and cellular ligands, and they are able to induce or block NK cell responses [30]. The cytotoxicity of NK cells is modulated by the balance between activating and inhibitory signals mediated by the receptors expressed on the cell surface [31]. Additionally, NK cells also express death receptors (Fas, DR4, and DR5) and ligands (FasL and TRAIL) [32], and TRAIL-DR4/5-mediated cytotoxicity plays an important role in eliminating the target cells [33]. As to the important soluble factors, NK cells produce IFN- $\gamma$, which inhibits viral replication directly, and secrete pro-inflammatory cytokines such as TNF- $\alpha$ and IL-6 along with various growth factors and chemokines [34]. According to the immunoblot data, the isolated EVs also contain these well-known anticancer mediators despite obvious interindividual variation in expression (Figure 4), suggesting that these factors might have also mediated the observed anticancer effect of the NKL-derived EVs as well.

For the identification of additional effector molecules that might have modulated the observed anticancer effect of the NKL-derived EVs, 2-DE-based proteome analysis was conducted, and it identified 37 different candidate proteins out of 49 proteins significantly increased in the NKL-derived EVs. Some of them are known to influence the function of NK and/or T cells, but the majority of them have no known relationship with NK and/or T cells (Table 1 and Figure 5).

For example, L-plastin, a family of actin-binding proteins, is one of the 37 proteins identified in the present study, and it was reported that L-plastin facilitates NKG2D-mediated NK cell migration [35] and T cell activation [36]. HSP90, another protein found to be increased in the NKL-derived EVs, is important for the regulation of phenotype and functional activity of human T lymphocytes and NK cells [37]. On the other hand, it was intriguing to notice that out of 37 increased spots, 5 spots were fibrinogen isotypes and 13 spots were $\beta / \gamma$-actin fragments (Table 1 ); these fibrinogen isotypes and $\beta / \gamma$-actin fragments also contributed to the observed anticancer effect of the NKL-derived EVs under certain circumstances, as evidenced by the antibody-mediated blocking experiments (Figure 6 and Figure S2). To be exact, although the effect was marginal, $\beta$-actin-neutralizing antibodies significantly attenuated the anticancer effect of the EV 1 in more than three different types of cancer cells (HepG2, MKN-74, and T98G) (Figure 6), and fibrinogen-neutralizing antibodies attenuated the anticancer effect of the EVs 1, 3, and 5 in HepG2 and that of the EVs 1, 2, and 4 in MKN-74 (Figure 6). This anticancer effect of $\beta$-actin and fibrinogen was further confirmed by the experiment using recombinant $\beta$-actin and fibrinogen without EVs (Figure 7).

These findings are surprising because $\beta$-actin and fibrinogen are the molecules least expected to contribute to the observed anticancer effect of the NKL-derived EVs. For example, the actin family is a family of globular multifunctional proteins that play roles in many critical cellular processes, including muscle contraction, cell motility, cell division, vesicle, cell signaling, and the establishment and maintenance of cell junctions and cell shape [38]. Regarding cancers, abnormal expression and/or polymerization of the actin cytoskeleton profoundly affect the invasiveness and metastasis of cancers [39]. More relevant to the present study, actin cytoskeleton rearrangement occurs during clathrin-mediated endocytosis [40], one of the major mechanisms by which EVs enter target cells [41]. Therefore, it may be feasible that the actin-neutralizing antibodies drawn into cancer cells during the first round of endocytosis bind to the actin filaments and thus hinder endocytosis. Nevertheless, 
this has to remain speculation without further empirical evidence to support it at this point. In addition, the present study did not cover the mechanism behind the increase of these unlikely molecules in the first place, nor did it identify the exact location of those molecules (i.e., bound to the surface of EVs or wrapped up inside). To answer all these unanswered questions, especially the important question of how those molecules contribute to the anticancer effect of the NKL-derived EVs, further studies are warranted.

The goal of the present study was not to test the feasibility of using the NKL-derived EVs for directly treating cancers; instead, it aimed to find any novel anticancer effectors of the NKL-derived EVs, as the identification of such effectors could make it possible to develop an anticancer cocktail to treat cancer even without using the original EVs. Furthermore, doing so could bypass the issues such as high heterogeneity or low reproducibility of the original EVs.

\section{Materials and Methods}

\subsection{Donors}

Human PBMCs and plasma used for the experiment were obtained from human blood samples of 5 healthy donors recruited at the International St. Mary's Hospital of Catholic Kwandong University. All donors provided informed consent to participate, and the study protocol was approved by the Institutional Review Board of the International St. Mary's Hospital, Catholic Kwandong University (IS18TSSE0043).

\subsection{Isolation of PBMCs/Plasma and Preparation of NKLs}

A house protocol describing the preparation of ex vivo expanded NKLs has been recently published [6]. Briefly, blood samples were collected from healthy donors, and PBMCs and plasma were collected from buffy coats and the upper aqueous phase of blood, respectively, by density gravity centrifugation (Ficoll-Paque, GE Healthcare, Piscataway, NJ, USA). For expansion and activation of NKLs, isolated PBMCs were supplemented with the following bioactive components: $0.5 \%$ or $10 \%$ autologous human plasma depending on the step, 3 different agonistic antibodies, and 3 different cytokines. The cells were cultured for 2 weeks to produce a sufficient number of NKLs. The following antibodies and cytokines were used: anti-human CD56 (555513, BD Biosciences, San Jose, CA, USA), anti-human CD16 (555403, BD Biosciences), anti-human CD355 (MAB1850-500, R\&D SYSTEMS, Minneapolis, MN, USA), IL-2 (653601261, Novartis, Whippany, NJ, USA), IL-12 (200-12, PeproTech, Rocky Hill, NJ, USA), and IL-18 (B003-2, R\&D Systems).

\subsection{Flow Cytometry}

To detect NK, NKT, and T cells using specific surface markers, NKLs were incubated with flow cytometry staining buffer for $30 \mathrm{~min}$ on ice and then washed twice with PBS. The staining buffer was a buffered saline solution containing fetal bovine serum (FBS, 26140079, Gibco by Life Technologies, Grand Island, NY, USA), 0.09\% sodium azide (S2002, Sigma-Aldrich, St. Louis, MO, USA) anti-human CD56 PE-Cyanine7 (25-0567-42, eBioscience, San Diego, CA, USA), anti-human CD16 PE-Cyanine7 (25-0168-42, eBioscience), and anti-human CD3 APC (17-0036-42, eBioscience) at a final concentration of $0.125 \mu \mathrm{g}$. The stained samples were analyzed and data were processed on an Acurri6 flow cytometer (BD Biosciences). The PBMCs were analyzed immediately after collecting blood from donors, whereas NKLs were examined by flow cytometry after two weeks of culturing using house-developed protocol. Though two experiments were performed on different days, we used the same flow cytometry conditions such as compensation, threshold, gating, and cell numbers to minimize possible technical variations between the two experiments. 


\subsection{Isolation of EVs from Culture Medium of NKLs}

Culture medium of NKLs ( $1 \mathrm{~L})$ and the same amount of fresh medium devoid of cells but containing an equal amount of autologous pooled plasma from 5 healthy donors were centrifuged at $480 \times g$ for $5 \mathrm{~min}$ and $2000 \times \mathrm{g}$ for $10 \mathrm{~min}$ to remove intact cells and cell debris [42]. The resulting supernatant was concentrated to $25 \mathrm{~mL}$ using a $100 \mathrm{kDa}$ MW cut-off filter membrane (PN OA100C12, Minimate TFF capsule, Pall Corporation, Ann Arbor, MI, USA). The concentrated conditioned media (CM) and control sample were further ultracentrifuged at $10,000 \times \mathrm{g}$ for $30 \mathrm{~min}$ twice to obtain NKL-derived EVs and control EVs (Figure 2A). Isolated EVs were stored at $-70{ }^{\circ} \mathrm{C}$ until use.

\subsection{Immunoblot Analysis}

The expression of known EV markers, cytokines, receptors, and ligands was examined by immunoblot analysis according to the methods previously published [43]. Briefly, EV lysates were prepared with RIPA buffer (89901, Thermo Scientific, Rockford, IL, USA) containing protease inhibitor and phosphatase inhibitor, and $40 \mu \mathrm{g}$ of EV lysates per lane was used for SDS-polyacrylamide gel electrophoresis (PAGE). The proteins were transferred to polyvinylidene fluoride (PVDF, Santa Cruz Biotechnology, Santa Cruz, CA, USA) membranes. The membranes were then incubated with appropriate primary antibodies and horseradish peroxidase (HRP)-conjugated secondary antibodies (Santa Cruz Biotechnology). Immunolabeled bands were visualized using an enhanced chemiluminescence (RPN2232, GE Healthcare) system. The following antibodies (purchased from Santa Cruz Biotechnology, Dallas, TX, USA) were used for the study: anti-CD154 (sc-74448), anti-L-selectin (sc-7297), anti-integrin $\alpha 1$ (sc-271034), anti-integrin $\alpha 3$ (sc-374242), anti-integrin $\beta 1$ (sc-374429), anti-CD63 (sc-365604), anti-FAS (sc-8009), anti-FAS ligand (sc-33716), anti-TRAIL (sc-8440), anti-DR4 (sc-8411), anti-DR5 (sc-166624), anti-NKG2D (sc-53501), anti-DNAM-1 (sc-376736), anti-NKp44 (sc-59342), anti-NKp46 (sc-53599), anti-IFN- $\gamma$ (sc-373727), anti-TNF $\alpha$ (sc-52746), anti-IL-6 (sc-28343), anti- $\beta$-actin (sc-517582), anti-FGG (sc-133226), anti-FGB (sc-271035), anti-ApoA-IV (sc-374543), anti-ApoE (sc-13521), anti-L-plastin (sc-133218), anti-VCP (sc-57492), and anti-HSP90 $\alpha / \beta$ (sc-13119).

\subsection{Culture of Cancer Cell Lines}

HepG2 (hepatoblastoma, HB-8065, ATCC, Manassas, VA, USA), SW-620 (colorectal carcinoma, CCL-227, ATCC), MKN-74 (stomach adenocarcinoma, 80104, Korea Cell Line Bank, Seoul, Korea), MCF-7 (breast adenocarcinoma, HTB-22, ATCC) and T98G (brain glioblastoma, CRL-1690, ATCC) cells were used. The SW-620, MKN-74, and MCF-7 cells were cultured in RPMI 1640 Medium (21870076, Gibco by Life Technologies) and the HepG2 and T98G cells were cultured in Minimum Essential Medium (MEM, 11090073, Gibco by Life Technologies) supplemented with 10\% heat-inactivated FBS, 2 mM L-glutamine (25030081, Gibco by Life Technologies), 1 mM sodium pyruvate (11360070, Gibco by Life Technologies), and 25 mM HEPES (15630080, Gibco by Life Technologies). The cells were maintained in a humidified atmosphere of $5 \% \mathrm{CO} 2$ and $95 \%$ air at $37^{\circ} \mathrm{C}$.

\subsection{Cell Viability and Cytotoxicity Assay}

Five different cancer cell lines (HepG2, SW-620, MKN-74, MCF-7, and T98G) were seeded at a density of $1 \times 10^{4}$ cells/well in a 96-well plate. After $24 \mathrm{~h}$, isolated EVs from CM of NKL were applied to the five cancer cells with different concentrations $(2,5,10$, and $20 \mu \mathrm{g} /$ well). After $24 \mathrm{~h}$ of culture, the supernatants were collected and objected to LDH assay to determine the cytotoxicity of EVs against cancer cells using a cytotoxicity detection kit (MK401, Takara, Nojihigashi, Kusatsu, Shiga, Japan). The viability of EV-treated cancer cells was measured using Ez-Cytox (Ex-3000, DOGEN, Seoul, Korea).

\subsection{Xenograft Model Using MCF-7}

Female athymic nude mice ( 5 weeks, Koatech, Pyeoungtaek, Korea) were used for the in vivo study. To evaluate the anticancer efficacy of the EVs isolated from CM of NKLs, the animals were 
subcutaneously bolus injected with MCF-7 $\left(3 \times 10^{6}\right.$ cells/head $)$ in the right flank. To facilitate breast tumor growth, the animals were also received $17 \beta$-estradiol valerate $(1 \mu \mathrm{g}$ in $100 \mu \mathrm{L}$ of peanut oil/head, E2758, Sigma-Aldrich) every three days starting from three days prior to the MCF-7 injection. Tumor volume (width $\times$ width $\times$ length/2) reached approximately $200 \mathrm{~mm}^{3}$ at week 7 , and the animals were randomly assigned to control EV group $(n=4)$ and NKL-derived EV group $(n=4)$. These two groups received control EVs and NKL-derived EVs (50 $\mu$ in $100 \mu \mathrm{L}$ of PBS), respectively, via tail vein once a week for 3 weeks. Control EVs were concentrated EVs with an equal amount of autologous pooled plasma from 5 donors. The tumor volume was measured once per week after MCF-7 cell injection. At the end of the in vivo study (10 weeks after the MCF-7 injection), the animals were sacrificed, and excised tumor weight was measured. All experimental procedures for animal studies were approved by the Committee for the Care and Use of Laboratory Animals of Catholic Kwandong University College of Medicine and were performed in accordance with the Committee's Guidelines and Regulations for Animal Care (CKU 01-2017-008).

\subsection{Preparation of Protein Samples for 2-DE}

For 2-DE analysis, proteins were isolated from the phenol-ethanol supernatant layer left over after the DNA precipitation step using TRIzol reagent (15596026, Thermo Fisher, Waltham, MA, USA). Precipitated proteins were dissolved in a rehydration buffer containing $7 \mathrm{M}$ urea, $2 \mathrm{M}$ thiourea, 4\% CHAPS, 20 mM DTT, 1 mM PMSF, 2\% immobilized pH gradient (IPG) buffer (Ampholyte 3/10, Bio-Rad, Hercules, CA, USA), and a trace of bromophenol blue. The proteins were then stored at $-80^{\circ} \mathrm{C}$ until analysis. Protein content was determined using Bradford protein assay (23236, Thermo Fisher).

\subsection{2-DE Analysis}

2-DE was performed in triplicate using EV protein samples ( $150 \mu \mathrm{g}$ per gel) from 5 healthy donors. IPG isoelectric focusing (IEF) of protein samples was performed at $\mathrm{pH}$ 4-7 with 18-cm IPG DryStrips (17-1233-01, GE Healthcare) using the Ettan IPGphor 3 system (GE Healthcare) according to the protocol recommended by the manufacturer. The IPG strips were passively rehydrated for $12 \mathrm{~h}$ in strip holders with $340 \mu \mathrm{L}$ of DeStreak Rehydration Solution (17600319, GE Healthcare), which contained $30 \mu \mathrm{g}$ of protein in each sample. IEF was executed using the advanced mode protocol: $1 \mathrm{~h}$ at $500 \mathrm{~V}, 3 \mathrm{~h}$ at $1000 \mathrm{~V}$, $6 \mathrm{~h}$ at $7000 \mathrm{~V}$, and finally at $7000 \mathrm{~V}$ until it reached $115 \mathrm{KVh}$. The gel strips were then placed onto a $12 \%$ polyacrylamide gel for resolving along the second dimension, using an Ettan DALTsix system. A total of 18 gels ( 3 gels from control and 15 gels from five individual samples) were visualized using silver staining and submitted to image analysis and peptide mass fingerprinting (PMF) [44].

\subsection{Image Acquisition and Data Analysis}

The gels were imaged using a UMAX PowerLook 1120 system (UMAX Technologies, Inc., Dallas, TX, USA, and modified ImageMaster 2-D software V4.95 (GE Healthcare) was used to compare the images. The detected spots from all gels were matched with those in the reference gel, which was selected from the control gels. Relative optical densities and relative volumes were calculated to correct differences in in-gel staining. The intensity volume of each spot was calculated using background subtraction and total spot volume normalization, and the resulting spot volume percentage was used for group comparison.

\subsection{Protein Identification}

Protein spots were excised, digested with trypsin (Promega, Madison, WI), mixed with $\alpha$-cyano-4-hydroxycinnamic acid (CHCA; Sigma-Aldrich) in 50\% acetonitrile/0.1\% trifluoroacetic acid, and used for MALDI-TOF analysis (Microflex LRF 20, Bruker Scientific LLC, Billerica, MA, USA) as described by Fernandez et al. [45]. Spectra were collected from 300 shots per spectrum over an $\mathrm{m} / \mathrm{z}$ range of 600-3000 and calibrated using a two-point internal calibration of trypsin autodigested peaks $(m / z$ 842.5099, 2211.1046). The peak list was generated using Flex Analysis 3.0. The thresholds 
used for peak-picking were 500 for the minimum resolution of monoisotopic mass and 5 for $\mathrm{S} / \mathrm{N}$. The search program MASCOT, developed by Matrixscience (http://www.matrixscience.com), was used, and the MASCOT probability-based molecular weight search (MOWSE) score was calculated for PMF. For database search, the following parameters were used: trypsin included as the cleaving enzyme, a maximum of one missed cleavage, iodoacetamide (Cys) as a complete modification, oxidation (Met) as a partial modification, monoisotopic masses, and a mass tolerance of $\pm 0.1 \mathrm{Da}$. The PMF acceptance criteria were based on probability scoring as follows: $-10 * \log (\mathrm{P})$, where $\mathrm{P}$ is the probability that an observed match is a random event, and a score greater than 68 is considered significant $(p<0.05)$.

\subsection{Antibody Blocking Assay by Neutralizing Antibodies}

To find causative factors associated with cytotoxicity of NKL-derived EVs against cancer, neutralizing antibodies of $\beta$-actin (PA1-46296, Thermo Fisher), fibrinogen (ab34269, Abcam, Cambridge, $\mathrm{UK})$, and isotype control (rabbit IgG, polyclonal; Abcam) were used. NKL-derived EVs (20 $\mu \mathrm{g} / \mathrm{well}$ in 96-well plate) mixed with individual neutralizing antibodies (500 ng/mL) were incubated for $2 \mathrm{~h}$ on ice, and the mixture was applied to 5 different cancer cell lines for viability and cytotoxicity assay.

\subsection{Recombinant $\beta$-Actin and Fibrinogen Treatment}

To verify the role of $\beta$-actin and fibrinogen, 5 different cancer cell line cells were treated with purified recombinant $\beta$-actin (APHL99-A, Cytoskelecton, Denver, CO, USA) and fibrinogen (ab62394, Abcam), and their effect on cancer cells was evaluated using LDH assay.

\subsection{Statistical Analysis}

All data were compared via one-way analysis of variance (ANOVA) using the Statistical Package for the Social Sciences (SPSS, version 14.0K) program. The data are expressed as means \pm standard error of measurement (SEM). Group means were considered significantly different at $p<0.05$, as determined by the protected least-significant difference (LSD) test when ANOVA indicated an overall significant treatment effect $(p<0.05)$.

\section{Conclusions}

In the present study, the anticancer potential of isolated EVs from expanded and activated NKLs was evaluated, and our data identified a number of molecules, such as Fas ligand, TRAIL, NKG2D, $\beta$-actin, and fibrinogen, as effector candidates based on the proteomic analysis and functional study. The results of the present study suggest the possibility of NK-cell-derived EVs as a viable immunotherapeutic strategy for cancer.

Supplementary Materials: The following are available online. Figure S1: Proteins increased in NKL-derived EVs. Figure S2: Examination of anticancer potential of NKL-derived proteins using neutralizing antibodies.

Author Contributions: Conceptualization, J.-W.C. and S.L. (Seahyoung Lee); methodology, J.H.K, S.H.H., and S.W.K.; software, S.W.K.; validation, J.-W.C. and S.L. (Soyeon Lim); data curation, J.H.K. and S.H.H.; formal analysis, S.L. (Soyeon Lim) and S.L. (Seahyoung Lee); investigation, S.L. (Soyeon Lim), J.H.K., S.H.H., and S.W.K.; resources, S.H.H., J.H.K., and K.-C.H.; writing-original draft preparation, J.-W.C. and S.L. (Soyeon Lim); writing-review and editing, K.-C.H. and S.L. (Seahyoung Lee); supervision, K.-C.H.; funding acquisition, J.-W.C., K.-C.H., and S.W.K.; project administration, S.L. (Seahyoung Lee). All authors have read and agreed to the published version of the manuscript.

Funding: This research was funded by the National Research Foundation of Korea (NRF) grant (NRF-2018R1A2B6008629 and NRF-2018R1D1A1B07049416).

Conflicts of Interest: The funders had no role in the design of the study; in the collection, analyses, or interpretation of data; in the writing of the manuscript; or in the decision to publish the results. J.W.C., S. Lim, S.W.K., and S. Lee are scientific advisory members of IMMUNISBIO Co. Ltd. and have received honorarium. 


\section{References}

1. Whiteside, T.L.; Demaria, S.; Rodriguez-Ruiz, M.E.; Zarour, H.M.; Melero, I. Emerging Opportunities and Challenges in Cancer Immunotherapy. Clin. Cancer Res. 2016, 22, 1845-1855. [CrossRef] [PubMed]

2. Farkona, S.; Diamandis, E.P.; Blasutig, I.M. Cancer immunotherapy: The beginning of the end of cancer? BMC Med. 2016, 14, 73. [CrossRef] [PubMed]

3. Vahedi, F.; Nham, T.; Poznanski, S.M.; Chew, M.V.; Shenouda, M.M.; Lee, D.; Ashkar, A.A. Ex Vivo Expanded Human NK Cells Survive and Proliferate in Humanized Mice with Autologous Human Immune Cells. Sci. Rep. 2017, 7, 12083. [CrossRef] [PubMed]

4. Dahlberg, C.I.; Sarhan, D.; Chrobok, M.; Duru, A.D.; Alici, E. Natural Killer Cell-Based Therapies Targeting Cancer: Possible Strategies to Gain and Sustain Anti-Tumor Activity. Front. Immunol. 2015, 6, 605. [CrossRef]

5. Sutlu, T.; Stellan, B.; Gilljam, M.; Quezada, H.C.; Nahi, H.; Gahrton, G.; Alici, E. Clinical-grade, large-scale, feeder-free expansion of highly active human natural killer cells for adoptive immunotherapy using an automated bioreactor. Cytotherapy 2010, 12, 1044-1055. [CrossRef]

6. Choi, J.W.; Lee, E.S.; Kim, S.Y.; Park, S.I.; Oh, S.; Kang, J.H.; Ryu, H.A.; Lee, S. Cytotoxic effects of ex vivo-expanded natural killer cell-enriched lymphocytes (MYJ1633) against liver cancer. BMC Cancer 2019, 19, 817. [CrossRef]

7. van der Pol, E.; Boing, A.N.; Gool, E.L.; Nieuwland, R. Recent developments in the nomenclature, presence, isolation, detection and clinical impact of extracellular vesicles. J. Thromb. Haemost. 2016, 14, 48-56. [CrossRef]

8. Balaj, L.; Lessard, R.; Dai, L.; Cho, Y.J.; Pomeroy, S.L.; Breakefield, X.O.; Skog, J. Tumour microvesicles contain retrotransposon elements and amplified oncogene sequences. Nat. Commun. 2011, 2, 180. [CrossRef]

9. Camussi, G.; Deregibus, M.C.; Bruno, S.; Cantaluppi, V.; Biancone, L. Exosomes/microvesicles as a mechanism of cell-to-cell communication. Kidney Int. 2010, 78, 838-848. [CrossRef] [PubMed]

10. Colombo, E.; Borgiani, B.; Verderio, C.; Furlan, R. Microvesicles: Novel biomarkers for neurological disorders. Front. Physiol. 2012, 3, 63. [CrossRef]

11. Chulpanova, D.S.; Kitaeva, K.V.; James, V.; Rizvanov, A.A.; Solovyeva, V.V. Therapeutic Prospects of Extracellular Vesicles in Cancer Treatment. Front. Immunol. 2018, 9, 1534. [CrossRef] [PubMed]

12. Feng, Q.; Zhang, C.; Lum, D.; Druso, J.E.; Blank, B.; Wilson, K.F.; Welm, A.; Antonyak, M.A.; Cerione, R.A. A class of extracellular vesicles from breast cancer cells activates VEGF receptors and tumour angiogenesis. Nat. Commun. 2017, 8, 14450. [CrossRef]

13. Tian, H.; Li, W. Dendritic cell-derived exosomes for cancer immunotherapy: Hope and challenges. Ann. Transl. Med. 2017, 5, 221. [CrossRef]

14. Raposo, G.; Stoorvogel, W. Extracellular vesicles: Exosomes, microvesicles, and friends. J. Cell Biol. 2013, 200, 373-383. [CrossRef] [PubMed]

15. Lotvall, J.; Hill, A.F.; Hochberg, F.; Buzas, E.I.; Di Vizio, D.; Gardiner, C.; Gho, Y.S.; Kurochkin, I.V.; Mathivanan, S.; Quesenberry, P.; et al. Minimal experimental requirements for definition of extracellular vesicles and their functions: A position statement from the International Society for Extracellular Vesicles. J. Extracell. Vesicles 2014, 3, 26913. [CrossRef]

16. Wen, C.; Seeger, R.C.; Fabbri, M.; Wang, L.; Wayne, A.S.; Jong, A.Y. Biological roles and potential applications of immune cell-derived extracellular vesicles. J. Extracell. Vesicles 2017, 6, 1400370. [CrossRef]

17. Andreu, Z.; Yanez-Mo, M. Tetraspanins in extracellular vesicle formation and function. Front. Immunol. 2014, 5, 442. [CrossRef]

18. Israels, S.J.; McMillan-Ward, E.M. CD63 modulates spreading and tyrosine phosphorylation of platelets on immobilized fibrinogen. Thromb. Haemost. 2005, 93, 311-318. [CrossRef] [PubMed]

19. van der Zee, P.M.; Biro, E.; Ko, Y.; de Winter, R.J.; Hack, C.E.; Sturk, A.; Nieuwland, R. P-selectin- and CD63-exposing platelet microparticles reflect platelet activation in peripheral arterial disease and myocardial infarction. Clin. Chem. 2006, 52, 657-664. [CrossRef]

20. Charoenviriyakul, C.; Takahashi, Y.; Morishita, M.; Matsumoto, A.; Nishikawa, M.; Takakura, Y. Cell type-specific and common characteristics of exosomes derived from mouse cell lines: Yeild, physicochemical properties and pharmacokinetics. Eur. J. Pharm. Sci. 2017, 96, 316-322. [CrossRef] 
21. Lhermusier, T.; Chap, H.; Payrastre, B. Platelet membrane phospholipid asymmetry: From the characterization of a scramblase activity to the identification of an essential protein mutated in Scott syndrome. J. Thromb. Haemost. 2011, 9, 1883-1891. [CrossRef] [PubMed]

22. Fourcade, O.; Simon, M.F.; Viode, C.; Rugani, N.; Leballe, F.; Ragab, A.; Fournie, B.; Sarda, L.; Chap, H. Secretory phospholipase A2 generates the novel lipid mediator lysophosphatidic ac id in membrane microvesicles shed from activated cells. Cell 1995, 80, 919-927. [CrossRef]

23. Andre, F.; Chaput, N.; Schartz, N.E.; Flament, C.; Aubert, N.; Bernard, J.; Lemonnier, F.; Raposo, G.; Escudier, B.; Hsu, D.H.; et al. Exosomes as potent cell-free peptide-based vaccine. I. Dendritic cell-derived exosomes transfer functional MHC class I/peptide complexes to dendritic cells. J. Immunol. 2004, 172, 2126-2136. [CrossRef] [PubMed]

24. Escudier, B.; Dorval, T.; Chaput, N.; Andre, F.; Caby, M.P.; Novault, S.; Flament, C.; Leboulaire, C.; Borg, C.; Amigorena, S.; et al. Vaccination of metastatic melanoma patients with autologous dendritic cell (DC) derived-exosomes: Results of thefirst phase I clinical trial. J. Transl. Med. 2005, 3, 10. [CrossRef]

25. Moore, C.; Kosgodage, U.; Lange, S.; Inal, J.M. The emerging role of exosome and microvesicle- (EMV-) based cancer therapeutics and immunotherapy. Int. J. Cancer 2017, 141, 428-436. [CrossRef]

26. Besse, B.; Charrier, M.; Lapierre, V.; Dansin, E.; Lantz, O.; Planchard, D.; Le Chevalier, T.; Livartoski, A.; Barlesi, F.; Laplanche, A.; et al. Dendritic cell-derived exosomes as maintenance immunotherapy after first line chemotherapy in NSCLC. Oncoimmunology 2016, 5, e1071008. [CrossRef]

27. Gehrmann, U.; Hiltbrunner, S.; Georgoudaki, A.M.; Karlsson, M.C.; Naslund, T.I.; Gabrielsson, S. Synergistic induction of adaptive antitumor immunity by codelivery of antigen with alpha-galactosylceramide on exosomes. Cancer Res. 2013, 73, 3865-3876. [CrossRef]

28. Zhu, L.; Kalimuthu, S.; Gangadaran, P.; Oh, J.M.; Lee, H.W.; Baek, S.H.; Jeong, S.Y.; Lee, S.W.; Lee, J.; Ahn, B.C. Exosomes Derived From Natural Killer Cells Exert Therapeutic Effect in Melanoma. Theranostics 2017, 7, 2732-2745. [CrossRef]

29. Di Pace, A.L.; Tumino, N.; Besi, F.; Alicata, C.; Conti, L.A.; Munari, E.; Maggi, E.; Vacca, P.; Moretta, L. Characterization of human NK cell-derived exosomes: Role of DNAM1 receptor in exosome-mediated cytotoxicity against tumor. Cancers 2020, 12, 661. [CrossRef]

30. Pegram, H.J.; Andrews, D.M.; Smyth, M.J.; Darcy, P.K.; Kershaw, M.H. Activating and inhibitory receptors of natural killer cells. Immunol. Cell Biol. 2011, 89, 216-224. [CrossRef]

31. Torelli, G.F.; Rozera, C.; Santodonato, L.; Peragine, N.; D’Agostino, G.; Montefiore, E.; Napolitano, M.R.; Monque, D.M.; Carlei, D.; Mariglia, P.; et al. A good manufacturing practice method to ex vivo expand natural killer cells for clinical use. Blood Transfus. 2015, 13, 464-471.

32. Wallin, R.P.; Screpanti, V.; Michaelsson, J.; Grandien, A.; Ljunggren, H.G. Regulation of perforin-independent NK cell-mediated cytotoxicity. Eur. J. Immunol. 2003, 33, 2727-2735. [CrossRef]

33. de Wilt, L.H.; Kroon, J.; Jansen, G.; de Jong, S.; Peters, G.J.; Kruyt, F.A. Bortezomib and TRAIL: A perfect match for apoptotic elimination of tumour cells? Crit. Rev. Oncol. Hematol. 2013, 85, 363-372. [CrossRef]

34. Walzer, T.; Dalod, M.; Robbins, S.H.; Zitvogel, L.; Vivier, E. Natural-killer cells and dendritic cells: "L'union fait la force". Blood 2005, 106, 2252-2258. [CrossRef]

35. Serrano-Pertierra, E.; Cernuda-Morollon, E.; Brdicka, T.; Hooejsi, V.; Lopez-Larrea, C. L-plastin is involved in NKG2D recruitment into lipid rafts and NKG2D-mediated NK cell migration. J. Leukoc. Biol. 2014, 96, 437-445. [CrossRef]

36. Wang, C.; Morley, S.C.; Donermeyer, D.; Peng, I.; Lee, W.P.; Devoss, J.; Danilenko, D.M.; Lin, Z.; Zhang, J.; Zhou, J.; et al. Actin-bundling protein L-plastin regulates T cell activation. J. Immunol. 2010, 185, 7487-7497. [CrossRef]

37. Bae, J.; Munshi, A.; Li, C.; Samur, M.; Prabhala, R.; Mitsiades, C.; Anderson, K.C.; Munshi, N.C. Heat shock protein 90 is critical for regulation of phenotype and functional activity of human T lymphocytes and NK cells. J. Immunol. 2013, 190, 1360-1371. [CrossRef]

38. Bunnell, T.M.; Burbach, B.J.; Shimizu, Y.; Ervasti, J.M. Beta-Actin specifically controls cell growth, migration, and the G-actin pool. Mol. Biol. Cell 2011, 22, 4047-4058. [CrossRef]

39. Guo, C.; Liu, S.; Wang, J.; Sun, M.Z.; Greenaway, F.T. ACTB in cancer. Clin. Chim. Acta 2013, 417, 39-44. [CrossRef]

40. Mooren, O.L.; Galletta, B.J.; Cooper, J.A. Roles for actin assembly in endocytosis. Annu. Rev. Biochem. 2012, 81, 661-686. [CrossRef] 
41. Mulcahy, L.A.; Pink, R.C.; Carter, D.R. Routes and mechanisms of extracellular vesicle uptake. J. Extracell. Vesicles 2014, 3, 24641-24654. [CrossRef] [PubMed]

42. Greening, D.W.; Xu, R.; Ji, H.; Tauro, B.J.; Simpson, R.J. A protocol for exosome isolation and characterization: Evaluation of ultracentrifugation, density-gradient separation, and immunoaffinity capture methods. Methods Mol. Biol. 2015, 1295, 179-209.

43. Choi, J.W.; Shin, S.; Lee, C.Y.; Lee, J.; Seo, H.H.; Lim, S.; Lee, S.; Kim, I.K.; Lee, H.B.; Kim, S.W.; et al. Rapid Induction of Osteogenic Markers in Mesenchymal Stem Cells by Adipose-Derived Stromal Vascular Fraction Cells. Cell. Physiol. Biochem. 2017, 44, 53-65. [CrossRef]

44. Kim, S.W.; Choi, J.H.; Mukherjee, R.; Hwang, K.C.; Yun, J.W. Proteomic identification of fat-browning markers in cultured white adipocytes treated with curcumin. Mol. Cell. Biochem. 2016, 415, 51-66. [CrossRef]

45. Fernandez, J.; Gharahdaghi, F.; Mische, S.M. Routine identification of proteins from sodium dodecyl sulfate-polyacrylamide gel electrophoresis (SDS-PAGE) gels or polyvinyl difluoride membranes using matrix assisted laser desorption/ionization-time of flight-mass spectrometry (MALDI-TOF-MS). Electrophoresis 1998, 19, 1036-1045. [CrossRef]

Sample Availability: Samples of frozen EVs from different donors are available from the authors.

Publisher's Note: MDPI stays neutral with regard to jurisdictional claims in published maps and institutional affiliations.

(C) 2020 by the authors. Licensee MDPI, Basel, Switzerland. This article is an open access article distributed under the terms and conditions of the Creative Commons Attribution (CC BY) license (http://creativecommons.org/licenses/by/4.0/). 